\title{
Regional Differences in Sugar-Sweetened Beverage Intake among US Adults
}

\author{
Sohyun Park, PhD, Lisa C. McGuire, PhD, and Deborah A. Galuska, PhD \\ S. Park is an epidemiologist, L. C. McGuire is lead epidemiologist, and D. A. Galuska is an \\ associate director for science, Division of Nutrition, Physical Activity, and Obesity, National \\ Center for Chronic Disease Prevention and Health Promotion, Centers for Disease Control and \\ Prevention, Atlanta, GA
}

\begin{abstract}
Background-Higher consumption of sugar-sweetened beverages (SSBs) is associated with obesity and type 2 diabetes, and the prevalence of obesity varies by geographic region. Although information on whether SSB intake differs geographically could be valuable for designing targeted interventions, this information is limited.
\end{abstract}

Objective-This cross-sectional study examined associations between living in specific census regions and frequency of SSB consumption among US adults using 2010 National Health Interview Survey data $(n=25,431)$.

Methods-SSB consumption was defined as the consumption of four types of beverages (regular sugar-sweetened carbonated beverages, fruit drinks, sports/energy drinks, and sweetened coffee/tea drinks). The exposure variable was census region of residence (Northeast, Midwest, South, and West). We used multivariable logistic regression to estimate adjusted odds ratios (aORs) and 95\% CIs for drinking SSBs after controlling for sociodemographic characteristics.

Results-Approximately $64 \%$ of adults consumed SSBs $\geq 1$ time/day. The odds of drinking SSBs $\geq 1$ time/day were significantly higher among adults living in the Northeast $(\mathrm{aOR}=1.13 ; 95 \% \mathrm{CI}=$ $1.01,1.26)$ but lower among adults living in the Midwest $(\mathrm{aOR}=0.70 ; 95 \% \mathrm{CI}=0.64,0.78)$ or West $(\mathrm{aOR}=0.78 ; 95 \% \mathrm{CI}=0.71,0.87)$ compared with those living in the South. By type of SSB, the odds of drinking regular soda $\geq 1$ time/day was significantly lower among adults living in the Northeast $(\mathrm{aOR}=0.51 ; 95 \% \mathrm{CI}=0.45,0.57)$, Midwest $(\mathrm{aOR}=0.86 ; 95 \% \mathrm{CI}=0.78,0.96)$, or West $(\mathrm{aOR}=0.56 ; 95 \% \mathrm{CI}=0.51,0.62)$ than those living in the South. The odds of drinking sports/energy drinks $\geq 1$ time/day were significantly lower among adults living in the West $(\mathrm{aOR}=$ $0.77 ; 95 \% \mathrm{CI}=0.64,0.93)$ than those living in the South. The odds of drinking a sweetened coffee/tea drink $\geq 1$ time/day were significantly higher among adults living in the Northeast (aOR $=1.60 ; 95 \% \mathrm{CI}=1.43,1.78)$ but lower among adults living in the Midwest $(\mathrm{aOR}=0.70 ; 95 \% \mathrm{CI}$ $=0.62,0.78)$ than those living in the South.

Address correspondence to: Sohyun Park, PhD, Division of Nutrition, Physical Activity, and Obesity, National Center for Chronic Disease Prevention and Health Promotion, Centers for Disease Control and Prevention, 4770 Buford Hwy, NE, Mailstop F77, Atlanta, GA 30341. spark3@cdc.gov. 
Conclusions-Total frequency of SSB consumption and types of SSB consumption differed by geographic region. Interventions to reduce SSB intake could consider regional variations in SSB intake, particularly when more local data are not available.

\section{Keywords}

Sugar-sweetened beverages; Soda; Fruit-flavored drinks; Sports and energy drinks; Geographic region

Obesity and diabetes are costly conditions affecting a large number of people and associated with excess morbidity and mortality. ${ }^{1,2}$ In the United States, the prevalence of both varies geographically. Approximately 35\% of US adults were classified as obese during 20112012 according to the National Health and Nutrition Examination Survey (NHANES). ${ }^{3}$ On the basis of self-reported weight and height data from the 2013 Behavioral Risk Factor Surveillance System (BRFSS), the prevalence of obesity among US adults differed by geographic regions and was higher in the South $(30.2 \%)$ and the Midwest (30.1\%) than the Northeast $(26.5 \%)$ and the West $(24.9 \%) .{ }^{4}$ In addition to the high prevalence of obesity in the United States, $12.3 \%$ of US adults had diabetes on the basis of 2009-2012 NHANES data. ${ }^{1}$ However, the percentage of US adults with diagnosed diabetes varied by state and ranged from $6.2 \%$ in Montana to $11.7 \%$ in Mississippi on the basis of 2012 BRFSS data. ${ }^{5}$ Of the 10 states with the highest prevalence of diagnosed diabetes among adults, nine were in the South. ${ }^{5}$ Understanding the extent to which risk factors for diabetes and obesity vary geographically can guide the design of targeted interventions.

One common risk factor is sugar-sweetened beverage (SSB) consumption. Higher consumption is related to obesity, ${ }^{6-8}$ type 2 diabetes, ${ }^{7,9,10}$ and other adverse health consequences among adults, including cardiovascular disease. ${ }^{7,11-13}$ The Scientific Report of the 2015 Dietary Guidelines Advisory Committee defined SSBs as "liquids that are sweetened with various forms of sugars. These beverages include, but are not limited to, soda, fruitades, and sports drinks." ${ }^{14}$ SSBs contribute significant energy to the diet of US adults. ${ }^{15}$ On the basis of the 2009-2010 NHANES data, approximately half of US adults consumed one or more SSB on a given day and almost $7 \%$ of their total daily energy intake came from SSBs. ${ }^{16}$

Variations in SSB intake by sociodemographic characteristics among adults have been well documented. ${ }^{17-21}$ For instance, high consumers of SSBs tend to be young adults, men, nonHispanic blacks, Mexican Americans, and low-income adults. ${ }^{17,18}$ However, only a limited number of studies suggest that SSB consumption may vary by geographic region. ${ }^{21-23}$ Two studies examined state-specific patterns using a limited number of states ${ }^{22,23}$ and found that SSB intake significantly differed by state. For example, Kumar and colleagues ${ }^{23}$ reported that the proportion of adults drinking SSBs at least once per day was the highest among adults residing in Mississippi (41.4\%) and the lowest among adults residing in Hawaii (20.4\%) using 2012 BRFSS data from 18 states. The second study ${ }^{21}$ used data from the 2010 HealthStyles Survey, on the basis of convenience sample of adults, and found that the proportion of adults consuming SSBs at least 2 times per day was highest among adults who lived in the East South Central region (32.0\%) and lowest among those who lived in the 
Pacific region (13.2\%). These studies either did not use nationally representative samples $^{21-23}$ or did not look at geographic differences in types of SSBs consumed. ${ }^{22,23}$ Identifying the extent that geographic regions are associated with types of SSBs using a large and nationally representative data source can provide needed information to better tailor interventions aimed at reducing SSB intake by region. Thus, the purpose of this analysis was to examine the association between census region of residence and total frequency of SSB consumption and types of SSB consumption among a representative sample of civilian noninstitutionalized US adults.

\section{METHODS}

\section{Sample and Survey Administration}

For this cross-sectional analysis, we used data from the 2010 National Health Interview Survey (NHIS) ${ }^{24}$ NHIS is a household survey conducted through in-person interviews that the Centers for Disease Control and Prevention National Center for Health Statistics has continuously conducted since 1957 . The NHIS uses a multistage sampling design to get a representative sample of civilian noninstitutionalized US households. Data on health and other characteristics of each family member in the household were collected, and additional information was obtained from one randomly selected child (Sample Child) or 1 randomly selected adult (Sample Adult) from the household. A total of 27,157 adults aged 18 years or older completed the Sample Adult Module in the 2010 NHIS. The 2010 Sample Adult Module had a response rate of $60.8 \%$ and collected information on sociodemographic characteristics, occupations, certain medical conditions, illness behavior/ health status, functional limitations, health behaviors, and health care access/use. During 2010, the Cancer Control Supplement was an additional part of the NHIS and was completed by the sample adults. The Cancer Control Supplement asks about dietary intake information and is administered every 5 years. The NCHS Research Ethics Review Board approved the NHIS.

Of the 27,157 adults who completed the Sample Adult Module and the Cancer Control Supplement, we excluded 1,726 who did not provide responses (ie, missing data, refused, or "don't know") on the consumption of any of the four SSBs (eg, regular sugar-sweetened carbonated beverages, fruit drinks, sports/energy drinks, and sweetened coffee/tea drinks). Adults with missing responses on marital status and education level were excluded from analyses when the variable was used. The remaining analytic sample included 25,431 adults. When comparing the analytic sample and the sample of respondents who were excluded, there were no differences between the samples by sex or race/ ethnicity. However, the analytic sample contained a slightly higher proportion of younger adults (aged 18 to 24 years) $\left(\chi^{2}\right.$ test $\left.P<0.05\right)$.

\section{Outcome Variables}

The outcome variables were frequencies of total SSB intake and the type of SSBs during the past month. The type of SSBs consumed was determined on the basis of survey respondents' answers to four questions: (1) "During the past month, how often did you drink regular soda or pop that contains sugar? Do not include diet soda"; (2) "During the past month, how often did you drink sweetened fruit drinks, such as Kool-Aid [Kraft Foods], cranberry and 
lemonade? Include fruit drinks you made at home and added sugar to"; (3) "During the past month, how often did you drink sports and energy drinks such as Gatorade [Quaker Oats Co], Red Bull [Red Bull Gmbh], and Vitamin Water [Coca-Cola Company]?"; and (4) "During the past month, how often did you drink coffee, including lattes, and tea, including bottled tea, that was sweetened with sugar or honey? Do not include drinks with things like Splenda [Johnson and Johnson] or Equal [Merisant]." For each beverage type, adults reported the number of times per day, per week, or per month that they consumed each type of beverage. Weekly or monthly frequency for each type of beverage was converted to daily intake frequency by dividing weekly intake frequency by 7 and monthly intake frequency by 30. To calculate frequency of total daily SSB intake, we summed the responses from intake of regular sugar-sweetened carbonated beverages, fruit drinks, sports/energy drinks, and sweetened coffee/tea drinks. For bivariate analyses, we generated three mutually exclusive categories $(0,>0$ to $<1$, or $\geq 1$ time/day) for total SSB intake and three mutually exclusive categories $(0,>0$ to $<1$, or $\geq 1$ time/day) for each type of SSB. For multivariable logistic regression analyses, frequency of consumption was dichotomized to differentiate daily consumers from nondaily consumers ( $<1$ or $\geq 1$ time/day) for total SSB and for each type of SSB $(<1$ or $\geq 1$ time/day).

\section{Exposure Variable}

The exposure variable was region of household residence and was categorized as the Northeast, Midwest, South, and West on the basis of the census region. Northeast region included Connecticut, Maine, Massachusetts, New Hampshire, New Jersey, New York, Pennsylvania, Rhode Island, and Vermont. Midwest region included Illinois, Indiana, Iowa, Kansas, Michigan, Minnesota, Missouri, Nebraska, North Dakota, Ohio, South Dakota, and Wisconsin. South region included Alabama, Arkansas, Delaware, District of Columbia, Florida, Georgia, Kentucky, Louisiana, Maryland, Mississippi, North Carolina, Oklahoma, South Carolina, Tennessee, Texas, Virginia, and West Virginia. West region included Alaska, Arizona, California, Colorado, Hawaii, Idaho, New Mexico, Montana, Oregon, Utah, Nevada, Washington, and Wyoming. ${ }^{25}$

\section{Covariates}

Mutually exclusive response categories for each covariate were created. Sociodemographic variables included were age ( 18 to 24,25 to 39,40 to 59 , or $\geq 60$ years); sex; race/ethnicity (non-Hispanic white, non-Hispanic black, Hispanic, or non-Hispanic other/multiracial); and marital status (married/domestic partnership or not married). Not married consisted of widowed, divorced, separated, or never married. Education level was categorized as less than high school graduate, high school graduate or recipient of a general education development certificate, some college, or college graduate. Annual family income was categorized as $<\$ 35,000, \$ 35,000$ to $\$ 74,999, \$ 75,000$ to $\$ 99,999, \geq \$ 100,000$, or did not know/ refused/missing.

\section{Statistical Analysis}

To examine the bivariate relationship of region of residence with sociodemographic characteristics and frequency of SSB intake, $\chi^{2}$ tests were used. Significance was set at 
$P<0.05$. Five independent multivariable logistic regression analyses were used to estimate adjusted odds ratio (aOR) and $95 \% \mathrm{CI}$ for the associations between region of residence and the odds of drinking total SSBs $\geq 1$ time/day as well as consumption of four types of SSBs $\geq 1$ time/day during the previous month with $<1$ time/day as the reference group. For the exposure variable of region, the South was used as a reference group because it was the region with the largest sample size. The multivariable logistic regression models controlled for the covariates of age, sex, race/ethnicity, marital status, education level, and annual family income. All statistical analyses were performed using SAS software (version 9.3, 2011, SAS Institute, Inc) and accounted for the complex sample design.

\section{RESULTS}

Sociodemographic characteristics of survey participants, stratified by region of residence, are presented in Table 1. Slightly more than one-half of the study population was aged $\geq 40$ years, was women, was non-Hispanic white, was married or in a domestic partnership, had some college education or reported being a college graduate, and $31.5 \%$ resided in a household with an annual family income of $\$ \$ 7,000$. All sociodemographic characteristics, except for sex, were significantly different by region of residence (see Table 1).

Overall, 64\% of adults reported consuming total SSBs $\geq 1$ time/day (Table 2). By type of beverages, $21 \%$ reported consuming regular sugar-sweetened carbonated beverages $\geq 1$ time/ day, $6.6 \%$ reported consuming fruit drink $\geq 1$ time/ day, 5.7\% reported consuming sports/ energy drink $\geq 1$ time/ day, and $43.5 \%$ reported consuming sweetened coffee/tea drink $\geq 1$ time/day. By region of residence, there were variations in consumption of total SSBs and type of SSBs ( $\chi^{2}$ test $P \searrow 0.0001$ ) (see Table 2). Approximately $68 \%$ of adults in the Northeast, $58.8 \%$ of adults in the Midwest, $66.7 \%$ of adults in the South, and $61.2 \%$ of adults in the West reported consuming total SSBs $\geq 1$ time/day. The South had the highest proportion of adults who consumed regular sugar-sweetened carbonated beverages, fruit drink, or sports/energy drink at least once per day. The Northeast had the highest proportion of adults who consumed sweetened coffee/tea drinks daily (Table 2).

The Figure shows the contribution of types of SSBs to the total reported mean frequency of SSB consumption for the entire sample and by region of residence. Overall, total reported mean frequency of SSB intake was 1.50 times/day. By region, the total reported mean frequency of SSB intake was 1.63 times/day for the Northeast, 1.62 times/day for the South, 1.43 times/day for the Midwest, and 1.31 times/day for the West. The most frequently consumed SSB was sweetened coffee/tea drinks, followed by regular soda, across the United States and consistently for each region. For example, the mean sweetened coffee/tea drink intake was 0.77 times/day for all adults, 1.04 times/day for the Northeast, 0.76 times/day for the South, 0.68 times/day for the West, and 0.66 times/ day for the Midwest.

Compared with adults living in the South, residents of the Northeast were significantly more likely to report consuming an SSB at least 1 time/day ( $\mathrm{aOR}=1.13$ ), whereas those living in the Midwest $(\mathrm{aOR}=0.70)$ and in the West $(\mathrm{aOR}=0.78)$ were less likely to report consuming an SSB at least 1 time/day after controlling for the covariates of age, sex, race/ ethnicity, marital status, education level, and annual household income (see Table 3). There 
were variations in the type of SSBs consumed by region of residence. Compared with adults living in the South, the odds of drinking a regular soda at least 1 time/day were significantly lower among adults living in the Northeast $(\mathrm{aOR}=0.51)$, the Midwest $(\mathrm{aOR}=0.86)$, and the West $(\mathrm{aOR}=0.56)$ and odds of drinking sports/energy drink $\geq 1$ times/day were significantly lower among adults living in the West $(\mathrm{aOR}=0.77)$. With respect to drinking sweetened coffee/tea drinks at least 1 time/day, the odds were significantly higher among those living in the Northeast $(\mathrm{aOR}=1.60)$ but lower among adults living in the Midwest $(\mathrm{aOR}=0.70)$ compared with people residing in the South. Consuming fruit drinks at least 1 time/day did not differ by region of residence after controlling for covariates (Table 3).

\section{DISCUSSION}

We found that almost two out of three adults (64\%) reported consuming SSBs at least once per day during the past month and that sweetened coffee/tea drinks were the most frequently consumed SSB among US adults, followed by regular soda. NHANES 2009-2010 found that approximately $50 \%$ of adults (aged $\geq 20$ years) drank SSBs on a given day using 24-hour recall data. ${ }^{16}$ In addition, we found that patterns in consumption varied by region. Our finding that sweetened coffee and teas were the most frequently consumed SSB adds to information collected in NHANES. In the 2009-2010 NHANES, regular sugar-sweetened carbonated beverages contributed approximately $55 \%$ of all energy from SSBs, followed by fruit drinks ( 19\%), sweetened coffee/tea drinks ( 18\%), and sports/energy drinks $(\sim 6 \%){ }^{16}$ Although sweetened coffees and teas were not the leading contributor to energy, they did account for $20 \%$ of the total energy from SSBs. ${ }^{16}$ This could be because of their high frequency in consumption. In addition, for some consumers, total added sugar intake from coffees and teas may be high even when frequency of consumption is low. Unlike regular sugar-sweetened carbonated beverages, the added sugar content varies widely for sweetened coffee/tea drinks and, unfortunately, these could not be separated for analyses. For example, a 13.7-oz ready-to-drink Mocha Frappuccino coffee drink (Starbucks Corp) has $280 \mathrm{kcal}$, including $48 \mathrm{~g}$ sugar, ${ }^{26}$ whereas a cup of brewed coffee with 2 packets of sugar has $22 \mathrm{kcal}$, including $5.6 \mathrm{~g}$ sugar. ${ }^{27}$ Because US adults regularly consume sweetened coffee/tea drinks, reducing sweetened coffee/tea drink intake might provide additional opportunities for targeted interventions to reduce overall consumption of SSBs.

Our finding of regional differences in the frequency of consumption could be taken into account when designing interventions to change SSB consumption. In our study, the frequency of consumption of total SSB and by type of SSB varied significantly by census region. Adults living in the Northeast had 13\% higher odds of consuming SSBs at least once per day compared with those living in the South, which was primarily due to the greater consumption of sweetened coffee/tea drinks in the Northeast. Those living in the Midwest and West had lower total frequency of SSB consumption; the odds of consuming SSB $\geq 1$ time/day was 30\% lower among adults living in the Midwest (due to lower intake of regular sodas and sweetened coffee/tea drinks), and it was $22 \%$ lower among adults living in the West (due to lower intake of regular sodas and sports/energy drinks) compared with those living in the South. Consistent with our findings of regional variation in the type of SSB consumption, a previous study found the pattern of consumption of types of SSBs (regular soda and fruit drink) differed slightly by state. ${ }^{23}$ For example, the prevalence of daily 
regular soda intake was highest in Mississippi, Tennessee, and Oklahoma. ${ }^{23}$ In addition, the two states with highest prevalence of daily SSB intake were in the South (Mississippi and Tennessee). ${ }^{23}$ Park and colleagues, ${ }^{21}$ in a related study, reported that the percentage of adults consuming SSBs $\geq 2$ times/day was the highest among adults living in the South (ie, East South Central and West South Central). ${ }^{21}$

Understanding why these regional differences exist would enhance intervention design and merits further investigation. For example, our findings regarding regional variations on the type of beverages that were commonly consumed could inform intervention efforts to come up with more targeted strategies for each region. Although the reasons are currently unclear, potential hypotheses include regional differences in beverage environments (eg, availability and access), marketing/advertising, and/or cultural norms. ${ }^{28-31}$ For example, a previous study found that the proportion of space in supermarket sales circulars for food groups varied by geographic region, and the South devoted significantly higher marketing space to sweets (mainly SSBs) than other regions. ${ }^{28}$ Future studies should examine potential reasons for regional variation in SSB intake because many factors could influence SSB intake in the United States.

To our knowledge, this was the first study to examine the relationship between reported SSB frequency of consumption (total SSB and by type of SSBs) and geographic regions using a large, nationally representative sample of US adults. However, this study has several limitations. First, the results were subject to potential reporting bias. The NHIS data on frequency of SSB consumption by sample adults were based on self-reported information. However, other studies have shown that estimates of beverage intake derived from responses to food frequency questionnaires are similar to estimates derived from responses to a 24hour dietary recall or to food records. ${ }^{32,33}$ Second, the frequency but not the volume of SSB intake was assessed. Thus, we cannot estimate actual energy intake from SSBs. Third, our study represents data collected in 2010 and may not reflect current patterns. However this is the most recent year that this question was asked on the NHIS. Finally, given that SSB intake is higher among young adults, ${ }^{16,18}$ our consumption estimates might be slightly higher than other surveys because the analytic sample contained a marginally higher proportion of younger adults.

\section{CONCLUSIONS}

Our findings show that SSB intake among US adults remains high, and patterns of consumption by SSB type vary by region. Intervention efforts to reduce obesity and diabetes incidence by reducing SSB intake among adults could consider the regional difference in SSB intake, particularly when local-level data are not available.

\section{Acknowledgments}

\section{FUNDING/SUPPORT}

There is no funding to disclose.

The findings and conclusions in this report are those of the authors and do not necessarily represent the offficial position of the Centers for Disease Control and Prevention. 


\section{References}

1. Centers for Disease Control and Prevention. [Accessed May 26, 2015] National diabetes statistics report, 2014. Estimates of diabetes and its burden in the United States. http://www.cdc.gov/diabetes/ pubs/statsreport14/national-diabetes-report-web.pdf

2. Centers for Disease Control and Prevention. [Accessed May 26, 2015] Adult obesity facts. http:// www.cdc.gov/obesity/data/adult.html

3. Ogden CL, Carroll MD, Kit BK, Flegal KM. Prevalence of childhood and adult obesity in the United States, 2011-2012. JAMA. 2014; 311(8):806-814. [PubMed: 24570244]

4. Centers for Disease Control and Prevention. [Accessed May 26, 2015] Obesity prevalence maps. http://www.cdc.gov/obesity/data/prevalence-maps.html

5. Centers for Disease Control and Prevention. [Accessed May 26, 2015] Data and statistics. State data. National Diabetes Surveillance System. http://gis.cdc.gov/grasp/diabetes/DiabetesAtlas.html

6. Ebbeling CB, Feldman HA, Osganian SK, Chomitz VR, Ellenbogen SJ, Ludwig DS. Effects of decreasing sugar-sweetened beverage consumption on body weight in adolescents: A randomized, controlled pilot study. Pediatrics. 2006; 117(3):673-680. [PubMed: 16510646]

7. Malik VS, Hu FB. Sweeteners and risk of obesity and type 2 diabetes: The role of sugar-sweetened beverages. Curr Diabet Rep. 2012; 12:195-203.

8. Malik VS, Pan A, Willett WC, Hu FB. Sugar-sweetened beverages and weight gain in children and adults: A systematic review and meta-analysis. Am J Clin Nutr. 2013; 98(4):1084-1102. [PubMed: 23966427]

9. Malik VS, Popkin BM, Bray GA, Despres JP, Willett WC, Hu FB. Sugar-sweetened beverages and risk of metabolic syndrome and type 2 diabetes: A meta-analysis. Diabetes Care. 2010; 33(11): 2477-2483. [PubMed: 20693348]

10. de Koning L, Malik VS, Rimm EB, Willett WC, Hu FB. Sugar-sweetened and artificially sweetened beverage consumption and risk of type 2 diabetes in men. Am J Clin Nutr. 2011; 93(6): 1321-1327. [PubMed: 21430119]

11. Duffey KJ, Gordon-Larsen P, Steffen LM, Jacobs DR Jr, Popkin BM. Drinking caloric beverages increases the risk of adverse cardiometabolic outcomes in the Coronary Artery Risk Development in Young Adults (CARDIA) Study. Am J Clin Nutr. 2010; 92(4):954-959. [PubMed: 20702604]

12. Stanhope KL, Bremer AA, Medici V, et al. Consumption of fructose and high fructose corn syrup increase postprandial triglycerides, LDL-cholesterol, and apolipoprotein-B in young men and women. J Clin Endocrinol Metab. 2011; 96(10):E1596-E1605. [PubMed: 21849529]

13. de Koning L, Malik VS, Kellogg MD, Rimm EB, Willett WC, Hu FB. Sweetened beverage consumption, incident coronary heart disease, and biomarkers of risk in men. Circulation. 2012; 125(14):1735-1741. [PubMed: 22412070]

14. The 2015 Dietary Guidelines Advisory Committee. [Accessed May 26, 2015] Scientific Report of the 2015 Dietary Guidelines Advisory Committee. Advisory Report to the Secretary of Health and Human Services and the Secretary of Agriculture. http://www.health.gov/dietaryguidelines/2015scientific-report/PDFs/Scientific-Report-of-the-2015-Dietary-Guidelines-Advisory-Committee.pdf

15. Welsh JA, Sharma AJ, Grellinger L, Vos MB. Consumption of added sugars is decreasing in the United States. Am J Clin Nutr. 2011; 94(3):726-734. [PubMed: 21753067]

16. Kit BK, Fakhouri TH, Park S, Nielsen SJ, Ogden CL. Trends in sugar-sweetened beverage consumption among youth and adults in the United States: 1999-2010. Am J Clin Nutr. 2013; 98(1):180-188. [PubMed: 23676424]

17. Ogden CL, Kit BK, Carroll MD, Park S. Consumption of sugar drinks in the United States, 20052008. NCHS Data Brief. 2011; (71):1-8.

18. Han E, Powell LM. Consumption patterns of sugar-sweetened beverages in the United States. J Acad Nutr Diet. 2013; 113(1):43-53. [PubMed: 23260723]

19. Park S, Onufrak S, Blanck HM, Sherry B. Characteristics associated with consumption of sports and energy drinks among US adults: National Health Interview Survey, 2010. J Acad Nutr Diet. 2013; 113(1):112-119. [PubMed: 23260728] 
20. Bleich SN, Wang YC, Wang Y, Gortmaker SL. Increasing consumption of sugar-sweetened beverages among US adults: 1988-1994 to 1999-2004. Am J Clin Nutr. 2009; 89(1):372-381. [PubMed: 19056548]

21. Park S, Onufrak S, Sherry B, Blanck HM. The relationship between health-related knowledge and sugar-sweetened beverage intake among US adults. J Acad Nutr Diet. 2014; 114(7):1059-1066. [PubMed: 24360502]

22. Park S, Pan L, Sherry B, Blanck HM. Consumption of sugar-sweetened beverages among US adults in 6 states: Behavioral Risk Factor Surveillance System, 2011. Prev Chronic Dis. 2014; 11:E65. [PubMed: 24762529]

23. Kumar GS, Pan L, Park S, Lee-Kwan SH, Onufrak S, Blanck HM. Sugar-sweetened beverage consumption among adults-18 states, 2012. MMWR Morb Mortal Wkly Rep. 2014; 63(32):686690. [PubMed: 25121711]

24. Centers for Disease Control and Prevention. 2010 National Health Interview Survey (NHIS) Public Use Data Release. NHIS Survey Description. Hyattsville, MD: National Center for Health Statistics; 2011.ftp://ftp.cdc.gov/pub/Health_Statistics/NCHS/Dataset_Documentation/NHIS/ 2010/srvydesc.pdf [Accessed May 26, 2015]

25. US Census Bureau. [Accessed May 26, 2015] Census regions and divisions of the United States. http://www2.census.gov/geo/pdfs/maps-data/maps/reference/us_regdiv.pdf

26. Starbucks Coffee Company. [Accessed May 26, 2015] Explore our menu. Bottled drinks. http:// www.starbucks.com/menu/drinks/bottled-drinks

27. US Department of Agriculture, Agricultural Research Service. [Accessed May 26, 2015] USDA National Nutrient Database for Standard Reference, release 27. http://ndb.nal.usda.gov/

28. Martin-Biggers J, Yorkin M, Aljallad C, et al. What foods are US supermarkets promoting? A content analysis of supermarket sales circulars. Appetite. 2013; 62:160-165. [PubMed: 23228904]

29. Tucker KL, Maras J, Champagne C, et al. A regional food-frequency questionnaire for the US Mississippi Delta. Public Health Nutr. 2005; 8(1):87-96. [PubMed: 15705249]

30. Pomeranz JL. Advanced policy options to regulate sugar-sweetened beverages to support public health. J Public Health Policy. 2012; 33(1):75-88. [PubMed: 21866177]

31. Centers for Disease Control and Prevention. [Accessed May 26, 2015] Division of Nutrition, Physical Activity and Obesity State Program Highlights. Limiting access to sugar-sweetened beverages. http://www.cdc.gov/obesity/downloads/limitingaccesstossbs.pdf

32. Hedrick VE, Comber DL, Estabrooks PA, Savla J, Davy BM. The beverage intake questionnaire: Determining initial validity and reliability. J Am Diet Assoc. 2010; 110(8):1227-1232. [PubMed: 20656099]

33. Hedrick VE, Savla J, Comber DL, et al. Development of a brief questionnaire to assess habitual beverage intake (BEVQ-15): Sugar-sweetened beverages and total beverage energy intake. J Acad Nutr Diet. 2012; 112(6):840-849. [PubMed: 22709811] 


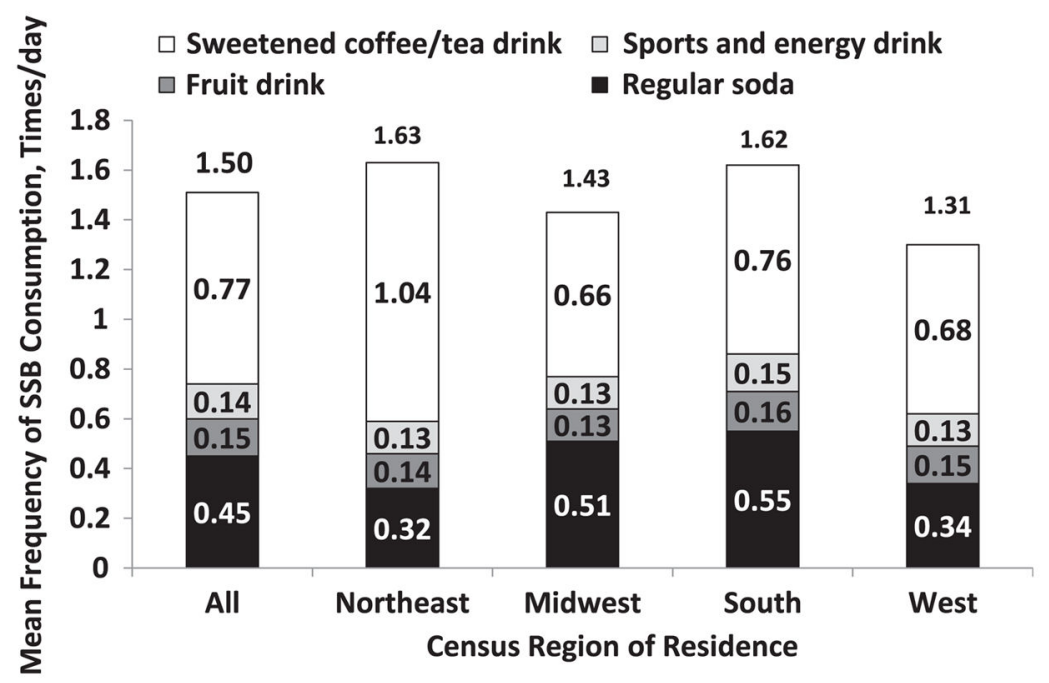

Figure.

Mean frequency of total sugar-sweetened beverage (SSB) consumption and the contribution of various types of beverages to the total SSB frequency of consumption for the study sample $(n=25,431)$ by region of residence among US adults, based on data from the National Health Interview Survey, 2010. Because of rounding, mean total frequency of SSB consumption may not match with the sum of each mean beverage frequency of consumption. 


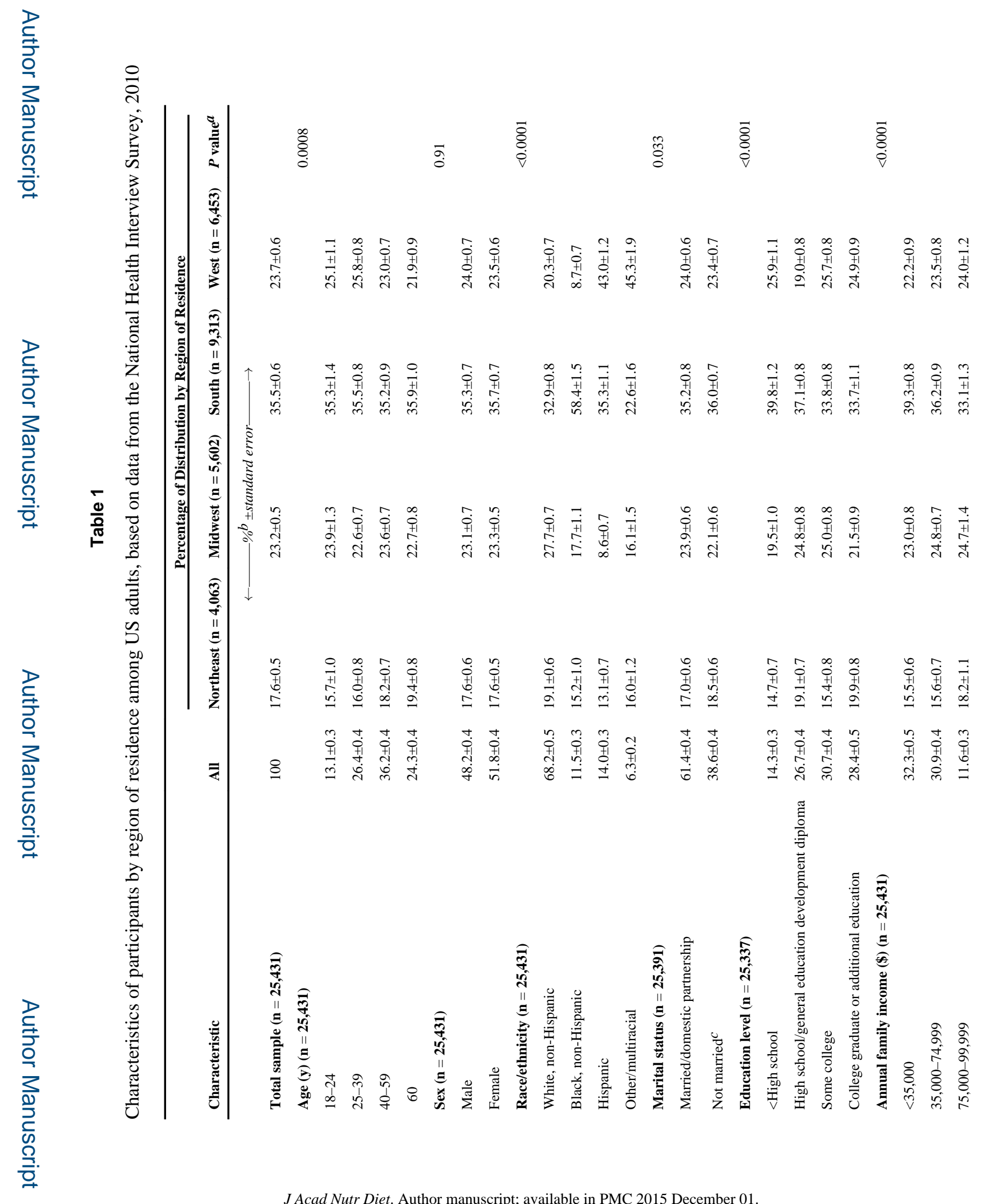




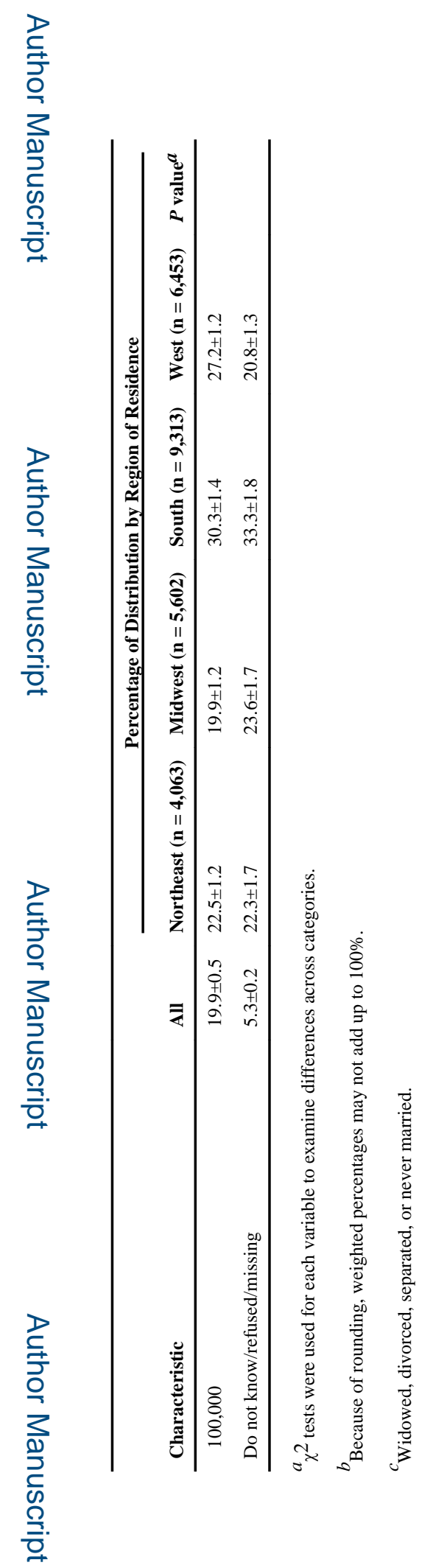




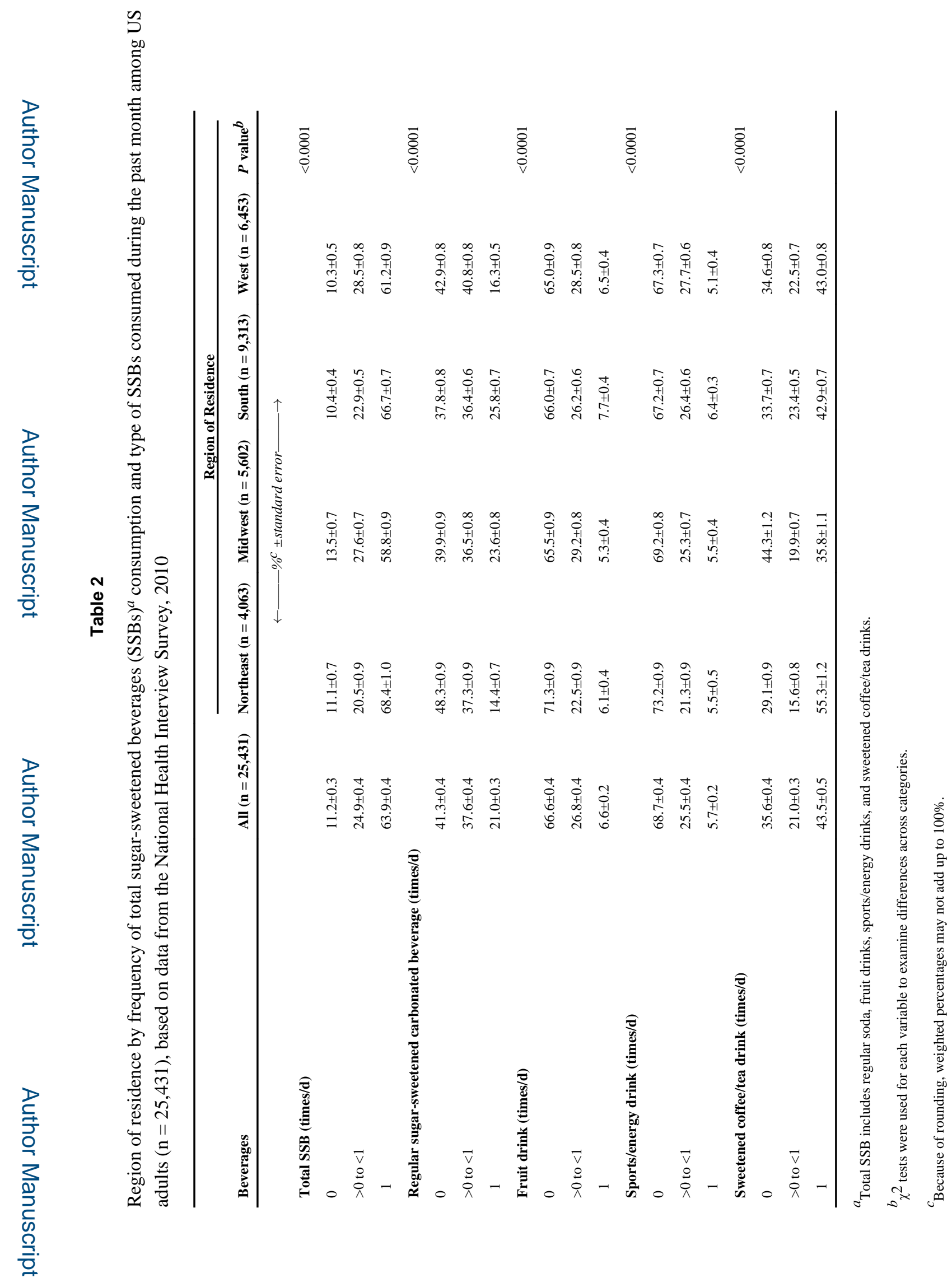

J Acad Nutr Diet. Author manuscript; available in PMC 2015 December 01. 
Park et al.

Page 14

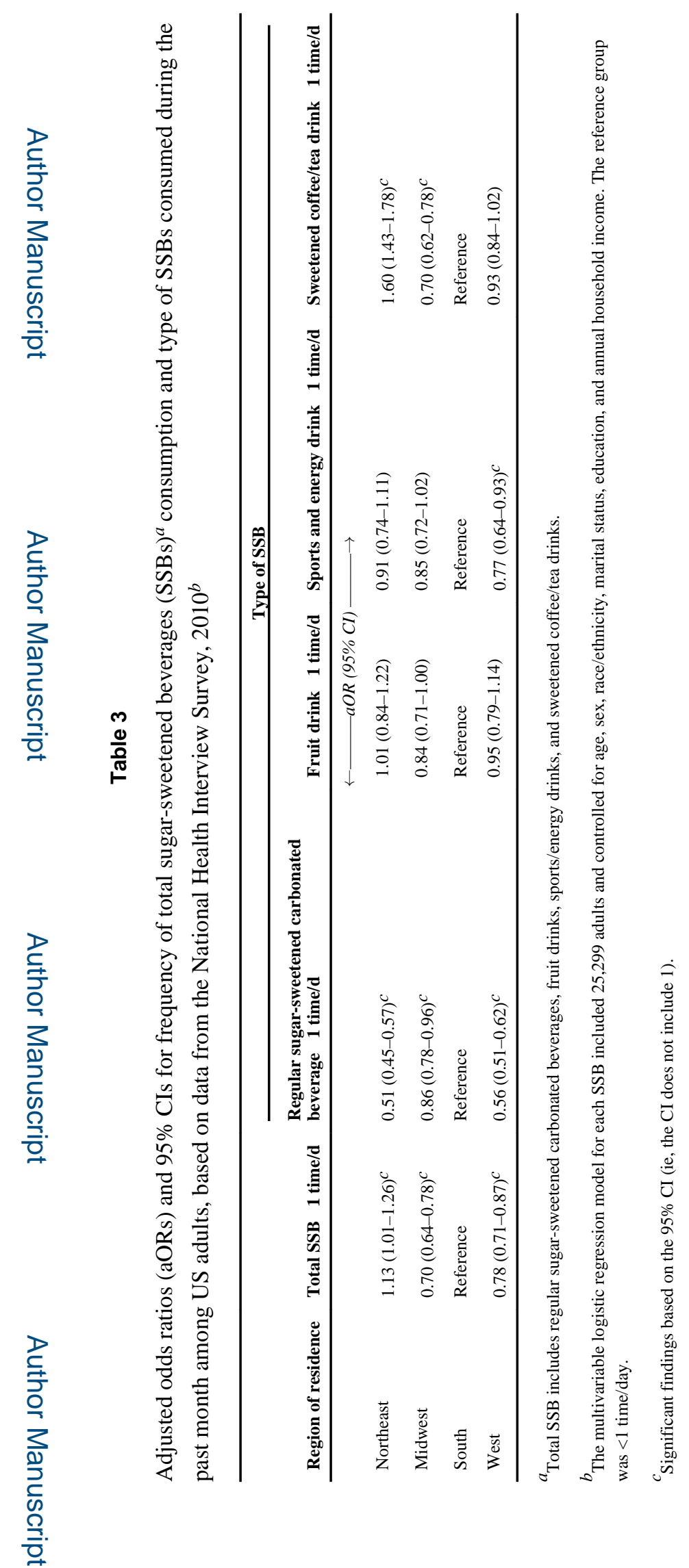

J Acad Nutr Diet. Author manuscript; available in PMC 2015 December 01. 